\title{
Evolving Wage Cyclicality in Latin America
}

\section{Luca Gambetti and Julián Messina}

\begin{abstract}
This paper examines the evolution of the cyclicality of real wages and employment in four Latin American economies, Brazil, Chile, Colombia, and Mexico, during the period 1980-2010. Wages were highly procyclical during the 1980s and early 1990s, a period characterized by high inflation. As inflation declined wages became less procyclical, a feature that is consistent with emerging downward wage rigidities in a low inflation environment. Compositional effects associated with changes in labor participation along the business cycle appear to matter less for estimates of wage cyclicality than in developed economies.
\end{abstract}

JEL classification: J24

Keywords: Bayesian estimation, downward wage rigidity, indexation, real wage cyclicality, time varying coefficients, vector autoregression

The debate about the extent and importance of nominal and real wage rigidities has been central in developed economies. Modern DSGE models, especially those used by central banks for policy evaluation, feature different forms of wage rigidity including nominal wage stickiness and partial indexation (e.g., Christiano, Eichenbaum, and Evans 2005 and Smets and Wouters 2007). Real wage rigidities are indeed fundamental to understand the trade-off between unemployment and inflation in models of the newKeynesian tradition (Blanchard and Gali 2007). Direct estimates of the extent and nature of downward wage rigidities are abundant in the literature. ${ }^{1}$ Similarly, the nature of real wage adjustments over the business cycle has been subject of substantial empirical scrutiny. ${ }^{2}$

In emerging countries the study of wage adjustments has traditionally attracted less attention from academics, perhaps because the high inflation and sharp recessions of the past were characterized by substantial wage flexibility. But macroeconomic stabilization, and in particular the rapid decline of inflation of recent decades, is likely to have brought substantial changes in wage rigidities. Disinflation has been particularly sharp in Latin American countries. The inflation rate declined from an average of 25 percent

Luca Gambetti is associate professor at Universitat Autònoma de Barcelona and Barcelona Graduate School of Economics; his email address is luca.gambetti@uab.es. Julián Messina (corresponding author) is lead economist at the Research Department of the Inter-American Development Bank; his email address is julianm@iadb.org. We thank Bill Maloney, Daniel Lederman, and seminar participants at the 2013 Latin American Economic Association Meetings for their helpful comments. Luca Gambetti acknowledges the financial support from the Spanish Ministry of Science and Innovation through grant ECO200909847 and the Barcelona Graduate School Research Network. The views expressed in this paper are solely the responsibility of the authors and should not be interpreted as reflecting the views of the Inter-American Development Bank.

1 See Dickens et al. (2007), Holden and Wulfsberg (2009), and the refereences therein.

2 See Abraham and Haltiwanger (1995) for an excellent literature review of the empirical literature and Messina, Strozzi, and Turunen (2009) for a more recent application to OECD countries. 
in the first half of the 1990s to 5 percent in second half of the 2000s. Figure 1 shows the recent inflation experience in four Latin American countries.

One channel through which a low inflation environment may increase the degree of real wage rigidity is by raising the likelihood of hitting binding downward nominal wage rigidities. If workers resist nominal wage cuts, firms operating in a low inflation environment subject to a negative shock are hampered to adjust real wages. Schmitt-Grohe and Uribe (forthcoming) suggest that emerging countries today display a substantial degree of downward nominal wage rigidity. Recent micro studies show that the decline of inflation rapidly introduced downward nominal wage rigidity in Uruguay and Brazil (Messina and Sanzde-Galdeano 2014) and in Mexico (Casarin and Juarez 2015). However, inflation stabilization is likely to ease wage indexation, possibly introducing through this channel some wage flexibility. ${ }^{3}$

This paper studies the changing importance of real wage rigidities in Latin American countries by looking at the evolution of real wage adjustments over the business cycle. Our interest in examining changes in real wage cyclicality precludes us from using traditional empirical approaches, which implicitly assume a constant comovement of wages and output through the period of study. In contrast to previous empirical literature, we assess the time-varying nature in the comovement of real wages and output by estimating a vector autoregression model with both time-varying coefficients and residuals volatilities. ${ }^{4}$ Our empirical approach properly accounts for the dynamic properties of the underlying data series and their comovement, as well as for changes in the underlying relationship between the different variables. ${ }^{5}$ We compute time-varying variances and covariances for four countries, Brazil, Chile, Colombia and Mexico, which are the four Latin America and Caribbean (LAC) economies with sufficiently long wage quarterly data. ${ }^{6}$

We find that wages were highly procyclical during the 1980s and early 1990s in three of the LAC countries studied, Brazil, Colombia and Mexico. Our Chilean data starts only in 1993 and exhibits mostly acyclical real wages. An important difference between Chile and the other three countries in the 1980s and 1990s is the rate of inflation. In Chile the inflation is low and stable, while Colombia exhibited doubledigit inflation rates, Mexico triple-digit, and even quadruple-digit inflation rates are observed in Brazil. Hand in hand with disinflation, Brazil and Colombia show clear signs of declining wage cyclicality over the sample period. The evidence in the case of Mexico goes in the same direction, but differences over time are smaller. Both differences across countries and over time within countries go in line with the emergence of downward real wage rigidities in the region during the macroeconomic stabilization of the late 1990s and 2000s. Largely consistent with this interpretation, we find that wages are more procyclical in booms than in recessions in Brazil, Colombia and Mexico, a feature that suggests that downward nominal wage rigidities are likely to be binding.

An important limitation of studying the cyclical behavior of real wages with aggregated data is that we cannot control for systematic changes in the composition of employment, which are likely to occur at business-cycle frequencies (Bils 1985). Low-earning workers typically enter the labor force during

3 Messina and Sanz-de-Galdeano (2014) show that inflation stabilization in Brazil reduced wage indexation associated with the minimum wage, and agents started bargaining wage growth in connection with the central bank inflation target. This process may have introduced some wage flexibility, as inflation expectations are heterogeneous across agents.

4 The model has become quite a popular tool in macroeconomics over the last few years and has been extensively employed to address questions related to the evolution of the structure of the economy (see Primiceri 2005; Canova and Gambetti 2009). Our analysis follows Gali and Gambetti (2009).

5 A number of authors, starting with Neftçi (1978), have stressed that accounting for the dynamic properties of the data series, such as persistence over time, is important. The dynamic properties of the data can indeed vary substantially across data series and countries, and as shown in Den Haan (2000), evidence on the cyclicality of prices based on simple static measures (e.g., comovement of detrended series) can be misleading. An application using the correlation between detrended compensation per employee and GDP in a large number of LAC countries is Aguilera et al. (2009).

6 In the case of Brazil and Mexico, our sample spans from the early 1980s to 2010. In Colombia and Chile the series are shorter, starting in 1990 and 1993, respectively. 


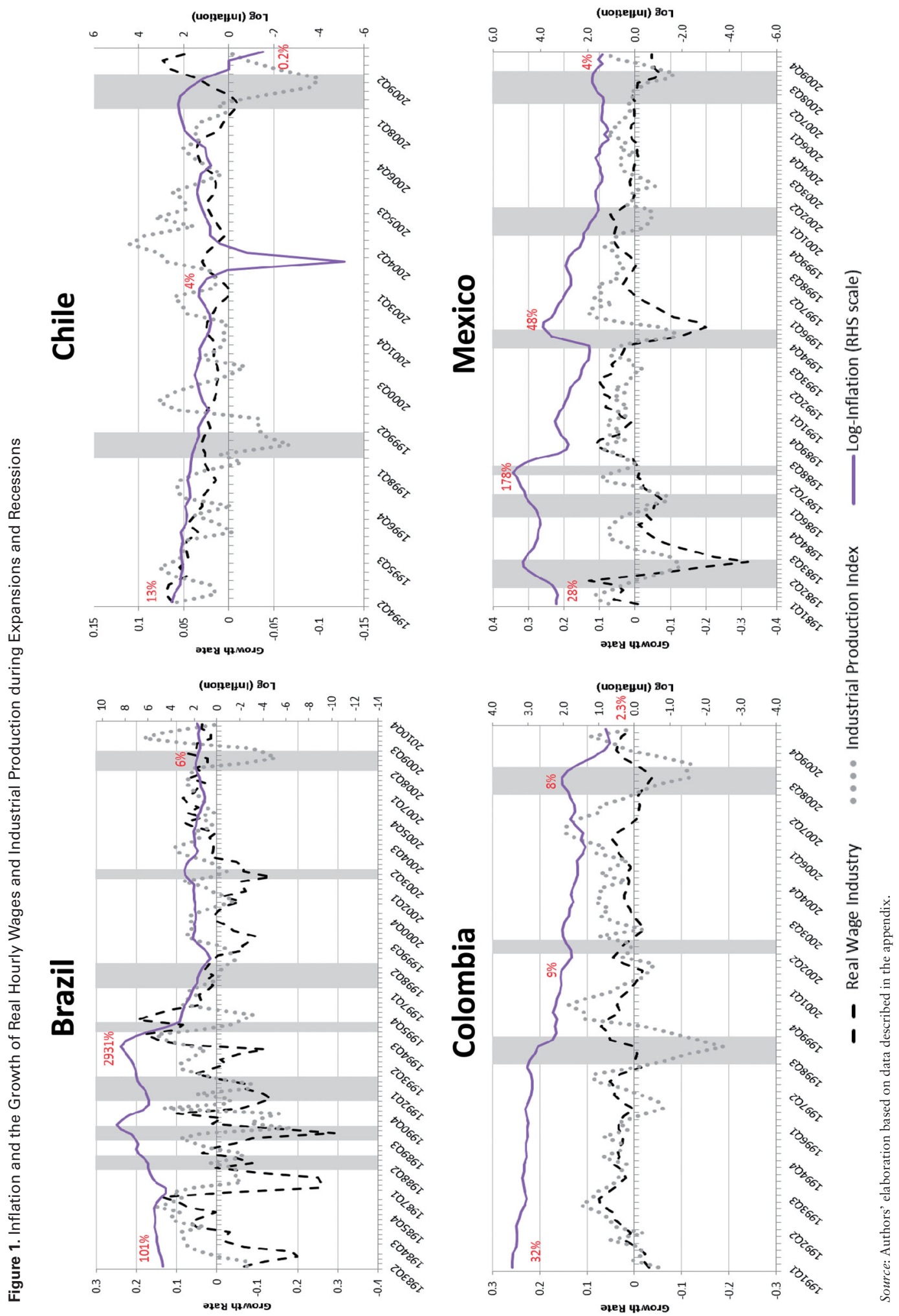


upswings and exit during downturns, biasing downwards the reaction of wages to the cycle evaluated at the macro level. This has been typically ignored in the macroeconomic literature but has been subject to substantial scrutiny in microeconometric studies, which find that this bias may be large (see Solon et al. 1994 and Carneiro, Guimaraes, and Portugal 2011). Wages often appear countercyclical, but once the bias is controlled for, a mild procyclicality emerges. The fact that wages are highly procyclical during the first years of our sample in three of our countries may suggest that this bias is less important in emerging economies. We further assess the importance of this bias in our context by looking at the Brazilian case in more detail, exploiting Brazilian micro data from the "Pesquisa Mensal de Emprego," one of the few labor force surveys in the developing world reporting long series of labor market data at a quarterly frequency. Interestingly, we find that controlling for observable characteristics of the employed population over the business cycle makes little difference to the macroeconomic estimates of real wage cyclicality in Brazil.

Our estimates are obtained for the manufacturing sector, where long series of quarterly wage data can be found. We exploit the Brazilian data to assess to what extent the results can be extrapolated to the rest of the economy by examining the cyclicality of aggregate wages in this country. The declining cyclicality found in the manufacturing sector is broadly consistent with what we find for the whole economy, suggesting that this is not a result experienced only in this particular sector.

Although our main focus is on the study of the cyclicality of real wages, we also investigate the parallel developments of employment adjustments over the business cycle. Interestingly, we find different patterns across countries. In Colombia, the decline of wage cyclicality is coupled with employment becoming much more procyclical. By contrast, declining wage cyclicality is accompanied by a parallel decline in the cyclicality of employment in Brazil. We find two forces that are likely to be behind this apparently puzzling result. First, the cyclicality of working hours (weakly) increased as wage cyclicality declined, suggesting a more important role for intensive margin adjustments. Second, the cyclicality of employment in the service sector is consistently lower than the comovement of employment and output in manufacturing. Hence, composition changes associated with the secular tertiarization of employment pushed the cyclicality of aggregate employment downwards.

The rest of the paper is organized as follows: Section I describes the data and econometric strategy. Section II summarizes the main results. Section III extends the basic results in several directions. First, it assesses the robustness of the results with respect to both changes in the composition of the labor force over the business cycle and differences in the cyclical behavior of wages across sectors. Second, it concentrates on the cyclicality of employment and examines differences across sectors and the intensive versus the extensive margin. Section IV concludes.

\section{Data and Econometric Approach}

Data

We use quarterly data for Brazil, Chile, Colombia, and Mexico. The key variables are: real consumer wages; employment industry index; and volume of industrial production index. All of these variables are obtained from national sources, as described in appendix 1. The indicator of real wage is the average hourly wage in the manufacturing sector deflated by the consumer price index (CPI). As Abraham and Haltiwanger (1995) and Messina, Strozzi, and Turunen (2009) have shown, the choice of the deflator is not innocuous. Consumer wages (those deflated with the CPI) tend to be more procyclical than producer wages (those deflated with producer price indices). We focus on consumer wages because this is the best measure to approximate worker's welfare. Naturally, the employment measure we use is the number of employees in the manufacturing sector. This leaves out from the analysis the intensive margin of labor market adjustment, a feature to which we shall return in section III. All of the variables are seasonally 
adjusted using the X12 methodology. Considering the rapid swings in the series that characterize these emerging economies, we take annualize growth rates rather than changes in the log series, which are customary in most of the literature.

We start the discussion of the data in figure 1, which shows the evolution of the inflation rate (right axis in a logarithmic scale) and the growth rates of real wages and industrial production in the four countries considered for the analysis. Gray areas indicate recessions, which are dated following Hardin and Pagan (2002). Note the rapid disinflation process in Brazil, Colombia, and Mexico. In Brazil, the inflation rate moves rapidly from almost 3,000\% in 1994Q3 to a lowest of $1.8 \%$ in 1998Q4. In Mexico and Colombia, the deceleration of price growth is slower and steadier, with both countries entering into single digit figures at the turn of the century.

The first aspect that stands out from wage data is that wages in Brazil and Mexico appear to have been more volatile than output during the first half of the sample, which coincided with the high inflation years (figure 1). This is particularly evident during the recessions. Real wages fell rapidly during the debt (1982) and Tequila (1995) crises in Mexico. In Brazil, the recessions of the 1990s were also characterized by rapid falls in real wages. This downward wage adjustment contrasts sharply with the adjustment of real wages during the Great Recession of 2008-2009. In the case of Mexico, real wages fell but to a lesser extent than real output. In Brazil, the rapid downward adjustment in production was not matched by a downward adjustment in real wages. The inability of wages to adjust downwards during recessions in a low-inflation environment is consistent with binding downward nominal wage rigidity, an issue to which we return in the econometric analysis. In Colombia wages also appear have been less sensitive to output in the second half of the sample, but the real wage did not decline during the recessions throughout the sample period. Manufacturing wages appear to be highly insensitive to the cycle in Chile, where inflation was stable and very close to zero through most of the period.

\section{Econometric Approach}

We study the evolution of labor market dynamics in Latin American countries using a time-varying coefficients vector autoregression model with stochastic volatility (Primiceri 2005). The analysis is carried out along the lines of Gali and Gambetti (2009). We use the model to compute time-varying second moments of the series of interest. The main advantage of the econometric approach adopted here is that correlations, variances, and other dynamic properties of the series are allowed to evolve over time in a very general and unconstrained fashion. This contrasts with most of the literature on wage cyclicality, where strong assumptions (e.g., a constant cyclicality) are imposed. As we shall see, these assumptions are severely violated in most of the countries studied.

Let $d_{t}=\left(y_{t}, w_{t}, e_{t}\right)^{\prime}$, where $y_{t}$ is industrial production growth, $w_{t}$ is real wage growth, and $e_{t}$ is employment growth. We assume that $d_{t}$ satisfies

$$
d_{t}=A_{0, t}+A_{1, t} d_{t-1}+\ldots+A_{p, t} d_{t-p}+\epsilon_{t}
$$

where $A_{0, t}$ is a vector of time-varying intercepts, $A_{i, t}$ are matrices of time-varying coefficients, $i=1, \ldots, p$, and $\epsilon_{t}$ is a Gaussian white noise with zero mean and time-varying covariance matrix $\Sigma_{t}{ }^{7}$

7 In practice we use $p=1$. However, we check the robustness of the results for $p=2$, and the results are unchanged. In these models, increasing the number of lags is problematic because it slows substantially the numerical algorithm. We acknowledge this as a limitation of the approach. The risk of under-parametrization (i.e., using few lags) is that some of the time variation in the parameters will be spuriously captured by the residuals variances. This is not a problem in our case because disentangling the sources of variation in the unconditional statistics is not among our goals. 
The dynamics of $d_{t}$, in particular correlations which are the focus of our analysis, can be studied using the "approximate" moving average representation

$$
d_{t}=\mu_{t}+\sum_{k=0}^{\infty} C_{k, t} \epsilon_{t-k}
$$

where $C_{0, t}=I, C_{k, t}=\mathcal{S}_{n, n}\left(\mathbf{A}_{t}^{k}\right), \mathbf{A}_{t}=\left(\begin{array}{c}A_{t} \\ I_{n(p-1)} 0_{n(p-1), n}\end{array}\right), A_{t}=\left[A_{1 t} \ldots A_{p t}\right]$, and $\mathcal{S}_{n, n}(X)$ is a function selecting the first $n$ rows and $n$ columns of the matrix $X$. The time-varying covariance matrix of $d_{i t}$ is given by

$$
V_{t}=\sum_{k=0}^{\infty} C_{k, t} \Sigma_{t} C_{k, t}^{\prime}
$$

The time-varying correlation between variable $j$ and $i$ is simply given by

$$
\rho_{t}^{i, j}=\frac{V_{t, j i}}{\sqrt{V_{t, j i} V_{t, i i}}}
$$

where $V_{t, j i}$ denotes the element $j, i$ of $V_{t}$. Estimation is performed using a Gibbs sampling algorithm. Further details of the model specification and estimation can be found in the appendix. The algorithm allows us to characterize the joint posterior distribution of all model parameters. Once the distribution is available, we draw realizations of $A_{t}$ and $\Sigma_{t}$ and compute a realization for $V_{t}$ and $\rho_{t, i j}$. By repeating the drawing procedure a large number of times, the distribution of variances and covariances can be characterized.

\section{Results}

\section{The Cyclicality of Real Wages and Employment}

Figure 2 shows the time-varying evolution of the standard deviation (i.e., $\sqrt{V_{t, i i}}$ ) of wages, employment, and industrial production (IP) in the four countries studied. The figure plots the mean and the $68 \%$ probability interval. The first aspect worth noting is the tremendous volatility of wages and employment in the two countries that experienced triple-digit inflation rates during the 1980s and first half of the 1990s, Brazil and Mexico. The volatility of employment and wages is about three to four orders of magnitude larger in this period compared to the other two countries and to their experiences during the 2000s. In contrast, the variance of wages in Chile and Colombia remains low and fairly stable throughout the sample period. We only observe a spike in the variances of employment in these two countries at the end of the 1990s.

How about the response of these three macro aggregates during the Great Recession? Nothing much happened in Brazil, Chile, and Colombia, perhaps with the exception of an increase in the variance of IP in Chile. In contrast, and consistent with the sharp economic downturn suffered by Mexico due to the collapse of trade with the United States, the variance of wages, employment, and output in this country increases rapidly during the last two years of the sample.

The relative volatility of the real wage with respect to output declines with inflation, in particular in those countries that experience hyperinflation in the 1980s. Li (2011) shows that a stylized fact of real wages in emerging countries is that they tend to be more volatile than output (in the range of $30-70 \%$ more volatile), while in the developed economies wages instead fluctuate less than output (on average $30 \%$ less). ${ }^{8}$ We next assess whether the relative volatilities have changed over the sample period.

$8 \quad \mathrm{Li}$ (2011) reports measures of volatility of output and wages and their comovement based on HP detrended series. Data sources vary substantially by country in Li (2011), and in many cases the wage variable is compensation per employee. Hence, measures of wage cyclicality become a relative measure of comovement of wages, employment and output. 
Figure 2. The Evolution of the Standard Deviation of Wages, Employment and Output
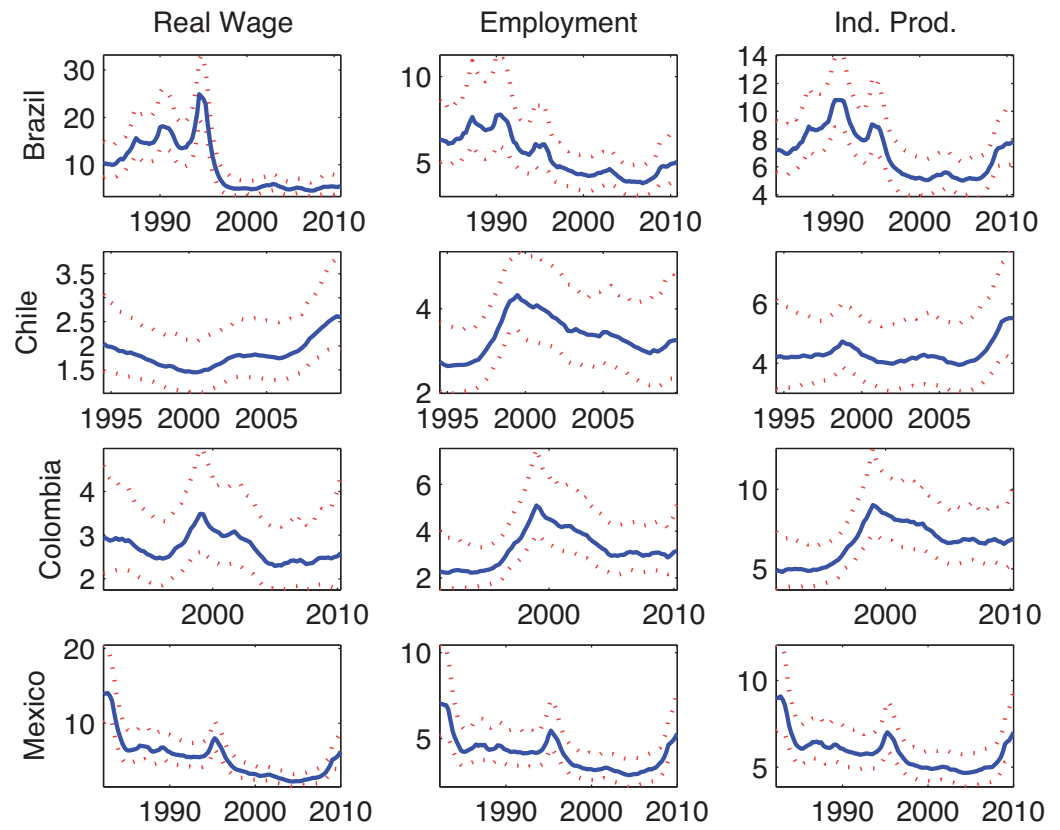

Source: Authors' elaboration based on data described in the appendix.

Figure 3 shows the ratio of the variance of the real wage and employment with respect to the industrial production index in the four countries studied. In Brazil and Mexico, the variance of real wages is higher than the variance of output during the high inflation years, declining rapidly thereafter. Interestingly, there is a spike in the relative volatility of wages in Brazil right at the time of the Real stabilization plan, in 1994. Once inflation is under control, the relative variance of wages moves from 1.5 to below 1 and continues to decline until 2010. In Mexico the stabilization of wages is slow moving but even more impressive. Starting with a relative volatility with respect to output close to 1.5 , it reaches 0.5 by 2005 , spiking up again during the great recession. Thus, Brazil and Mexico started behaving much more in line with developed country estimates with macroeconomic stabilization. In contrast, the relative volatility of wages in Chile and Colombia is always below the volatility of output and much more in line with that reported by $\mathrm{Li}$ (2011) for high income countries.

Declines in the volatility of wages are coupled with reductions in the employment volatility with respect to output, suggesting progressive stabilization in the labor markets of each respective country as time evolves. The sole exception is observed in Mexico during the great recession, which displays a spike in the volatility of employment associated with the rapid increase in unemployment.

Figure 4 presents the time-varying cyclicality of wages and employment in the four LAC countries studied, measured by the time-varying correlation, that is, $\rho_{t}^{i, j}$. The figure plots the mean and the $68 \%$ probability interval. Each row presents a country and each column an estimated pair-wise measure of comovement: wages and output (column 1) and employment and output (column 2). The first aspect worth stressing is that, with the exception of Chile, wages appear to be fairly procyclical in the first years of the sample. Concentrating on the comovement between wages and output, the average of the median posterior cyclicality up to the year 1995 in Brazil is around 0.45 , close to 0.7 in Colombia and 0.35 in Mexico. These numbers are on the upper range of the estimated cyclicality of wages in most OECD 
Figure 3. The Relative Variance of Wages and Employment with Respect to Output
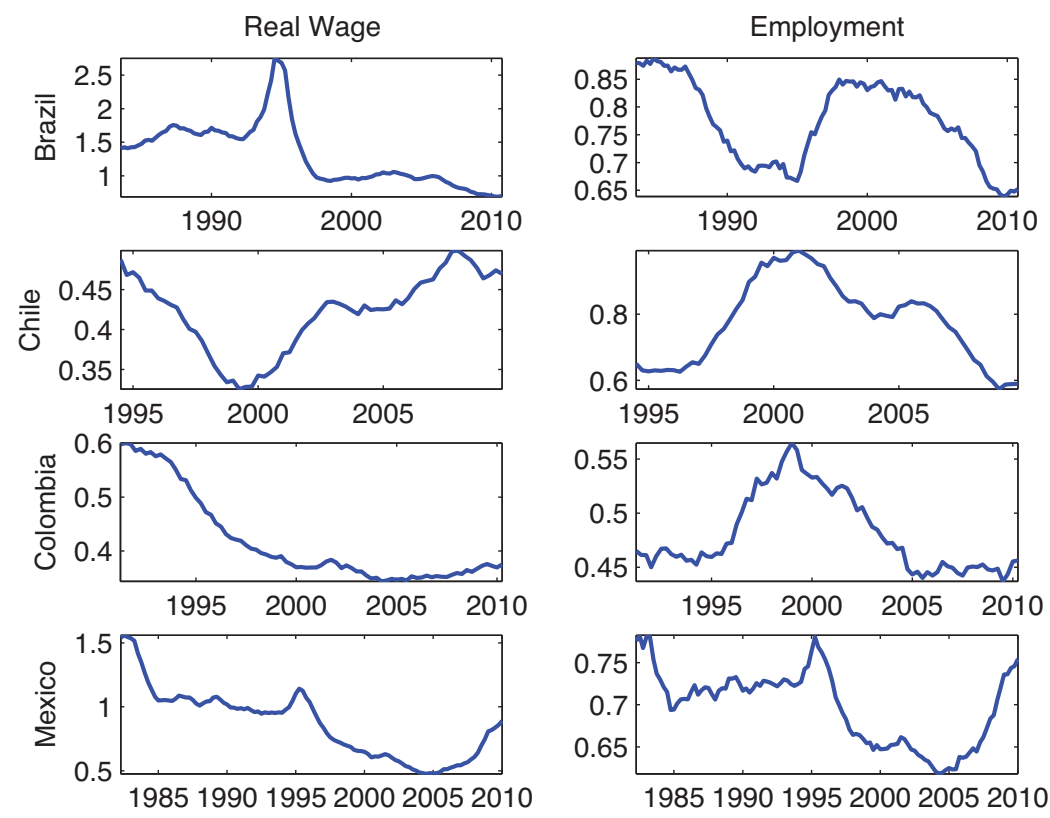

Source: Authors' elaboration based on data described in the appendix.

Figure 4. The Evolving Cyclicality of Real Wages and Employment
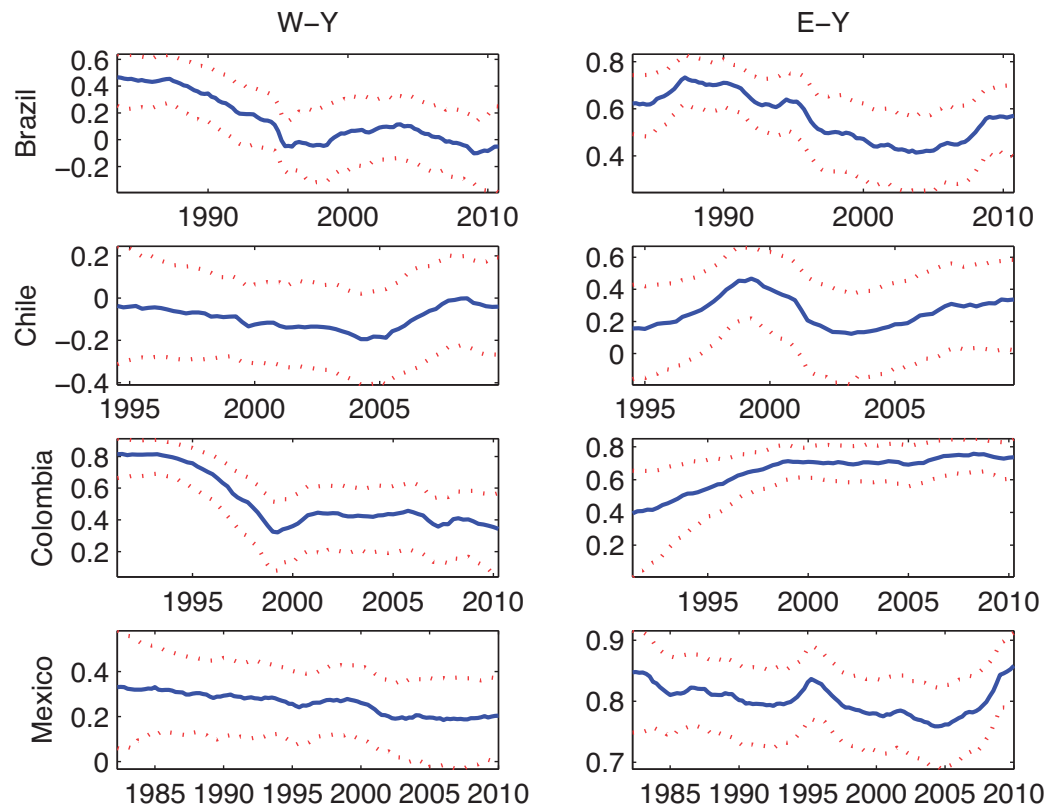

Note: W-Y and E-Y denote the cyclicality of wages and employment, respectively. Source: Authors' elaboration based on data described in the appendix. 
countries, a fact also highlighted by $\operatorname{Li}$ (2011). Using two dynamic approaches for 18 OECD countries, Messina et al. (2009) found that the cyclicality of wages ranges from -0.38 in New Zealand to 0.41 in Japan. In the United States, wages are mildly procyclical, at 0.28 .

There are clear signs of a declining cyclicality over time in Colombia, Brazil, and to a lesser extent, in Mexico. By 2010 wages are acyclical in Brazil, in sharp contrast with a correlation of 0.4 in the 1980s. Interestingly, the decline in the cyclicality of wages in Brazil is nonlinear. The correlation of wages and output declines rapidly around 1994, when Brazil introduces the macroeconomic stabilization program that led to the stabilization of inflation (the Real stabilization plan). In the case of Colombia, the elasticity of wages is reduced by half by the end of the sample, from 0.8 in the early 1990s to below 0.4 in 2010 . In Mexico the cyclicality of wages declines much more modestly, while in Chile wages appear to be relatively acyclical with no clear pattern over the short period of time for which data is available (19932010). ${ }^{9}$

We construct a measure of the differences in the cyclicality before and after 1995 in order to assess the statistical significance of the observed changes. The median difference pre- and post-1995 in Brazil is 0.28, and the 16th and 84th percentiles of the posterior distribution correspond to 0.09 and 0.46 , respectively, underscoring that the correlation between real wages and output was larger in the first part of the sample. In Colombia the differences are even sharper. The median difference is 0.36 and the 16 th $(84$ th $)$ percentile is $0.22(0.50)$. In Mexico the evidence suggests a smaller reduction, with a median difference pre- and post-1995 of 0.07 , and the $16 \mathrm{th}(84 \mathrm{th})$ percentiles is $-0.06(0.22)$.

There is not necessarily a one-to-one correspondence between the time evolution of the cyclicality of wages and employment. The different paths in Brazil, Mexico, and Colombia (second column of figure 4) illustrate this with clarity. The employment cyclicality in Mexico remained fairly stable throughout the period of study, in spite of the mild reduction of wage cyclicality. In Brazil the cyclicality of employment declines. The posterior median difference pre- and post-1995 is 0.18 , and the 16 th $(84$ th) percentile is $0.07(0.28)$. This apparently puzzling result may suggest that other margins of adjustment (e.g., hours worked) may be changing as well, an issue to which we shall return in section III. In contrast, the reduction of the cyclicality of wages in Colombia is associated with an increase in the comovement between employment and output. The posterior distribution of difference pre- and post-1995 has an estimated median of -0.22 , and the 16 th and 84 th percentiles are -0.43 and -0.03 , respectively.

\section{Business Cycle Asymmetries. Excess Cyclicality during Expansions?}

We examine further the potential asymmetries in the response of wages and employment to output by calculating the difference in the cyclicality of each variable between expansions and recessions. ${ }^{10}$ If downward nominal wage rigidities are important, we may expect excess cyclicality of wages during expansions.

We define the differential cyclicality between expansions and recessions for wages $\left(D C^{w, y}\right)$ and employment $\left(D C^{l, y}\right)$ as follows:

$$
\begin{aligned}
& D C^{w, y}=1 / T_{1} \sum_{t_{1} \in \text { boom }} \rho_{t_{1}}^{w, y}-1 / T_{2} \sum_{t_{2} \in \text { recession }} \rho_{t_{2}}^{w, y} \\
& D C^{l, y}=1 / T_{1} \sum_{t_{1} \in \text { boom }} \rho_{t_{1}}^{l, y}-1 / T_{2} \sum_{t_{2} \in \text { recession }} \rho_{t_{2}}^{l, y},
\end{aligned}
$$

where $T_{1}$ is the number of quarters of expansion and $T_{2}$ the number of periods of recession.

9 Note however that the inflation rate in Chile is fairly low and stable through the period of analysis. Chile achieved inflation stability in 1982. Unfortunately, there is no wage data covering the hyper-inflation period, but our results for the other three countries suggest that wages may have been more procyclical during this period.

10 The turning points to date expansions and recessions are obtained from the series of industrial production with the Bry-Boschan Quarterly (BBQ) algorithm (Hardin and Pagan (2002)). 
Table 1. The Cyclicality of Wages and Employment: Differences between Booms and Recessions

\begin{tabular}{|c|c|c|c|}
\hline & $16^{\text {th }}$ & $50^{\text {th }}$ & $84^{\text {th }}$ \\
\hline \multicolumn{4}{|l|}{ Brazil } \\
\hline$D C^{w, y}$ & 0.0177 & 0.1277 & 0.2293 \\
\hline$D C^{l, y}$ & 0.1666 & 0.1913 & 0.2187 \\
\hline \multicolumn{4}{|l|}{ Chile } \\
\hline$D C^{w, y}$ & -0.1597 & -0.0612 & 0.0403 \\
\hline$D C^{l, y}$ & -0.0062 & 0.1117 & 0.2108 \\
\hline \multicolumn{4}{|c|}{ Colombia } \\
\hline$D C^{w, y}$ & 0.2118 & 0.2747 & 0.3349 \\
\hline$D C^{l, y}$ & 0.2723 & 0.3291 & 0.3794 \\
\hline \multicolumn{4}{|l|}{ Mexico } \\
\hline$D C^{w, y}$ & 0.0414 & 0.0881 & 0.1375 \\
\hline$D C^{l, y}$ & 0.2613 & 0.2819 & 0.2992 \\
\hline
\end{tabular}

Note: Estimates of the median, $16^{\text {th }}$ and $84^{\text {th }}$ percentile of the posterior distribution of excesss cyclicality during booms versus recessions, calculated according to equation 3.

Source: Authors' elaboration based on data described in the appendix.

Table 1 displays the median and the $68 \%$ probability interval for the difference between the average correlation coefficient in booms and recessions. Perhaps not surprisingly, wages tend to be more responsive to output during expansions in the three countries that exhibit highly procyclical wages. The median excess procyclicality of wages (difference in the cyclicality between expansions and recessions) is 0.13 in Brazil, 0.09 in Mexico, and 0.27 in Colombia. Examining the 16th and 84th percentiles of the posterior distribution suggests a clear shift to the right in the comovement between wages and output during booms. This is indicative of asymmetries in wage setting, whereby upward mobility in wages during expansions is more easily obtained than real wage cuts during recessions. With regards to employment, we find a mild excess procyclicality during expansions in all countries except Chile. In Colombia and Mexico the excess procyclicality of wages during expansions exceeds that of employment, reinforcing a role for downward nominal wage rigidities during recessions.

\section{Extensions}

In this section we exploit the access to high quality micro data for Brazil, the "Pesquisa Mensal de Emprego" (PME), to extend the analysis in three directions. We first assess how changes in the composition of the labor force along the business cycle may have contaminated our previous estimates. If workers who enter and exit the labor force in different phases of the cycles are different, estimates of the wage cyclicality in aggregate data may be biased. Secondly, we extend the study of the employment and wage cyclicality beyond the manufacturing sector by analyzing wages and employment in the whole economy. Finally, we focus on the cyclical behavior of employment and hours in different sectors to understand why a decline in the cyclicality of wages did not translate into increases in the cyclicality of employment. ${ }^{11}$

\section{Changes of Employment Composition along the Business Cycle}

Workers are heterogeneous, and those who exit and enter the labor market along the business cycle are not a representative subsample of the labor force. In particular, low-earning workers and those with less

11 Unfortunately, a long time series of quarterly micro data of similar characteristics to the PME is not available in the other countries. Some aspects discussed in this section are shared across the board. This is the case of the secular tertiarization of the economy, for example. Informality declined during the 2000s in all four countries, but the intensity of changes and levels are very different, with Chile displaying much lower informality than Brazil and Colombia. Thus, a great deal of caution should be used before extrapolating this section's results for Brazil to the other three countries. 
attachment to the labor market tend to enter the labor force during expansions and exit during recessions. Solon et al. (1994) show that such composition changes are important and that failing to control for the time-varying characteristics of the labor force in the employed population introduces a downward bias in estimates of the cyclicality of wages in the United States. Similar conclusions are reached for other developed countries (e.g., Carneiro, Guimaraes, and Portugal 2011).

In developing countries, the importance of compositional effects in estimates of the cyclicality of wages have been largely ignored. Large informal sectors in developing countries typically act as a buffer, expanding in recessions and contracting in expansions and thus limiting swings of unemployment or inactivity (Bosch and Maloney 2008). The lower cyclicality of unemployment could, in principle, ameliorate the wage cyclicality bias. However, another potential composition bias arises from the movement in and out of informality, especially if the wage gap between formal and informal employment is large.

In order to assess the importance of compositional effects in estimates of the cyclicality of wages, we exploit the micro data in the PME and proceed as follows. First, we estimate a standard Mincer regression of individual wages

$$
\log \left(w_{i t}\right)=\alpha+\beta X_{i t}+\tau_{t}+\epsilon_{i t},
$$

where $X_{i t}$ includes quadratic terms on years education and age, and $\tau_{t}$ are quarterly dummies. ${ }^{12}$ In a second stage, we use the coefficients of the quarterly dummies $\left(\hat{\tau}_{t}\right)$ as our main wage variable in the analysis. These estimated coefficients are naturally the average wage in the quarter once changes in the education and experience of the employed population have been taken into account.

Figure 5 shows the evolution of the cyclicality of real wages in Brazil before and after controlling for compositional effects. The graphs on the left hand panel reproduce our previous estimates, which do not take into account changes in the composition of the employed population over the cycle. The right hand panels show the impact of controlling for observable characteristics of the labor force on the cyclicality and volatility of all variables. Perhaps surprisingly, we find that changes in the composition of the workforce do not have a major impact on the cyclicality of wages. As before, we observe a decline in the comovement of wages and output throughout the sample period.

\section{Manufacturing vs. Whole Economy}

Our analysis so far was confined to the manufacturing sector. We can exploit the PME, which is representative of all sectors in urban areas in Brazil, to examine possible differences in the cyclical behavior of real wages across sectors. Since we are interested in the comovement between wages and output, the output indicator we consider when we evaluate the cyclicality of real wages for the whole economy is aggregate GDP.

Figure 6 shows the evolution of the cyclical behavior of real wages for the whole economy. The graphs on the left hand side show the cyclicality of wages and employment when the raw series of real wages are considered. On the right hand side, we show instead the cyclicalities of employment and wages obtained with the series of wages that control for observable worker characteristics. The broad patterns described above remain unchanged when all sectors of the economy are considered. The correlation of wages and output starts at 0.4 in 1984 , falling gradually to become countercyclical during the 2000 s. The pattern is similar to that observed for the manufacturing sector, although the reduction in wage cyclicality is even more pronounced when we consider the whole economy.

The broad conclusion of a decline of wage cyclicality is unaffected once changes in the composition of the labor force have been netted out. However, controlling for compositional effects has a somewhat larger impact when we consider the whole economy series (right hand panels). Wage cyclicality starts

12 The regression is conducted after trimming the observations in the bottom $1 \%$ and top $99 \%$ of the distribution and does not include public sector workers. 
Figure 5. The Role of Compositional Effects: Real Wage and Employment Cyclicality in Brazil
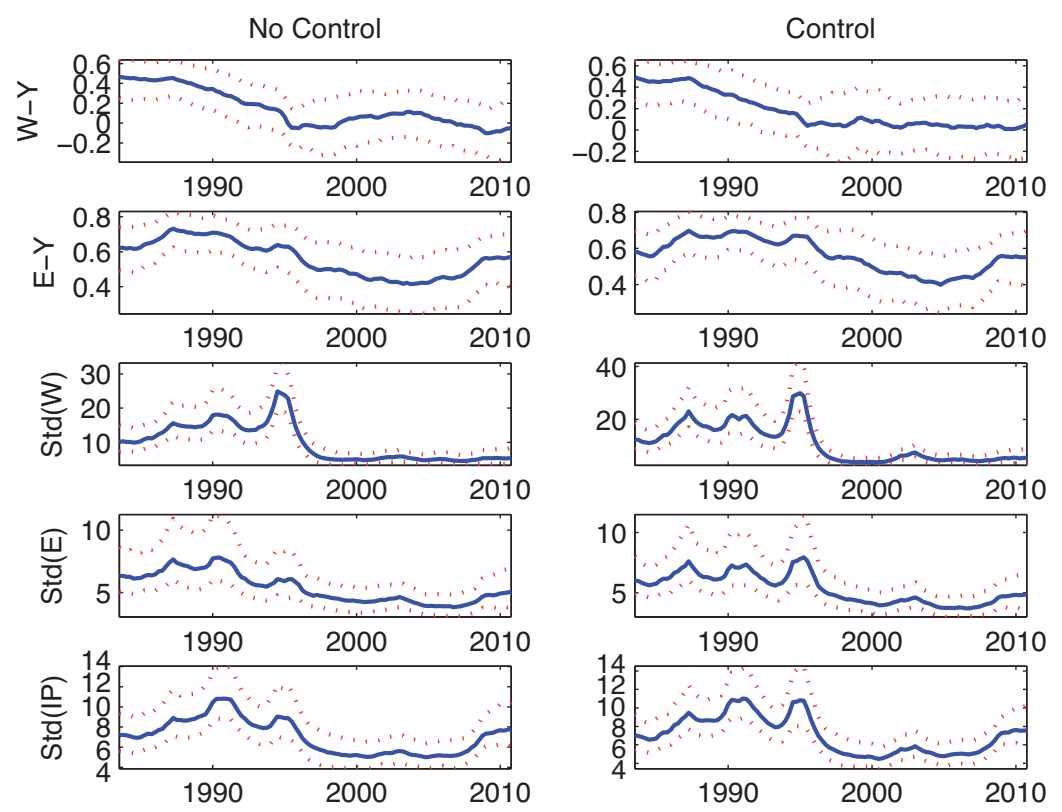

Notes: W-Y and E-Y denote the cyclicality of wages and employment, respectively. Std. denotes the standard deviation of industrial production (IP), employment (E) and wages (W). In the first column (No Control) the wage series corresponds to the raw data. In the second column (Control) the wage series has been purged of compositional effects due to changes in labor force participation.

Source: Authors' elaboration based on data described in the appendix.

Figure 6. The Evolving Cyclicality of Real Wages and Employment in the Whole Economy
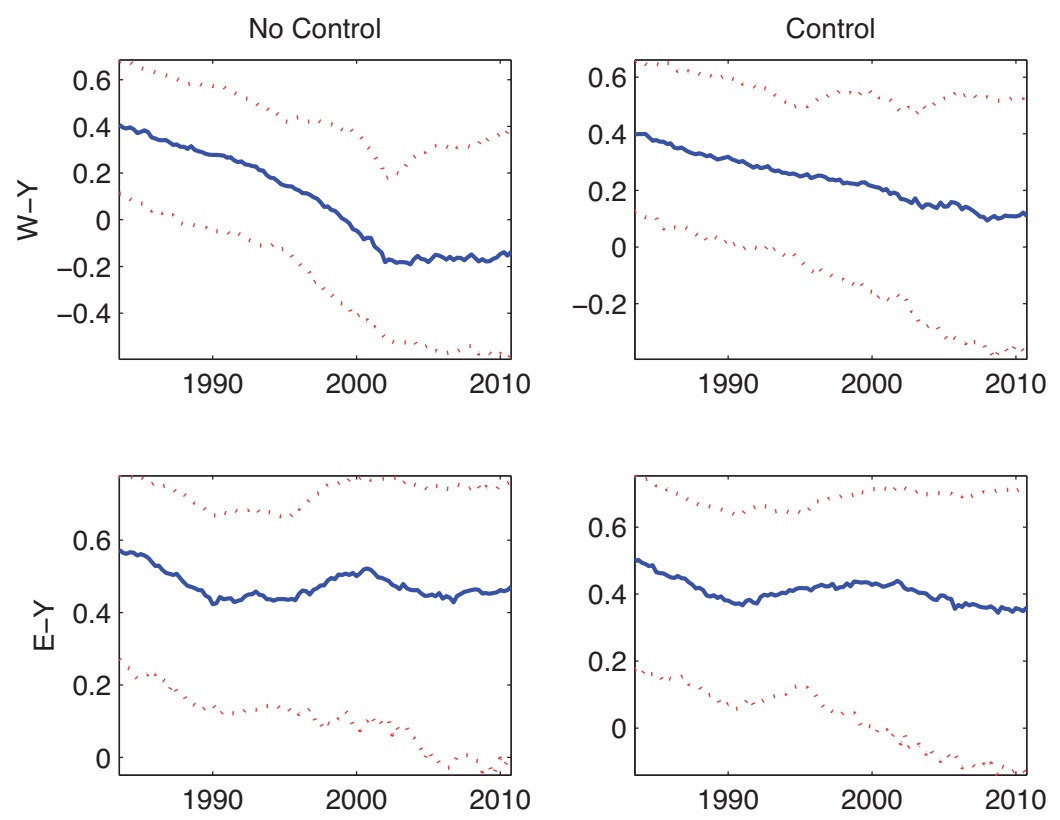

Notes: W-Y and E-Y denote the cyclicality of wages and employment, respectively. In the first column (No Control) the wage series corresponds to the raw data. In the second column (Control) the wage series has been purged of compositional effects due to changes in labor force participation.

Source: Authors' elaboration based on data described in the appendix. 
Table 2. Changes in the Cyclicality of Employment before and after 1995: Intensive vs. Extensive Margin and Differences Across Sectors

\begin{tabular}{lccr}
\hline & 16th & 50th & 84th \\
\hline$D C_{s}^{l, y}-$ employment - whole economy & -0.038 & -0.013 & 0.014 \\
$D C_{s}^{l, y}-$ hours - whole economy & -0.071 & -0.028 & 0.016 \\
$D C_{s}^{l, y}-$ employment - services & -0.053 & -0.002 & 0.049 \\
$D C_{s}^{l, y}-$ employment - formal & -0.032 & -0.006 & 0.020 \\
$D C_{s}^{l, y}-$ employment - informal & -0.160 & -0.107 & -0.048 \\
\hline
\end{tabular}

Note: Estimates of the median, 16th and 84th percentile of the posterior distribution of the differences in the cyclicality of employment before and after 1995 by sector as defined in footnote 14 .

Source: Authors' elaboration based on data described in the appendix.

at almost an identical level in 1984 (strongly procyclical, at 0.4 ) and declines through the three decades but at a slower pace. ${ }^{13}$ More importantly, wages purged of compositional changes are still procyclical during the 2000s, with an estimated elasticity of 0.1 , while they were countercyclical in the raw data. The implication is that changes in the composition of the labor force are more important when we consider the economy as a whole, an issue to which we return in the next section.

\section{The Stability of Employment Cyclicality: Intensive Margin vs. Sectoral Composition}

The declining wage cyclicality and the excess cyclicality of wages during booms presented above are suggestive of an increasing role for downward wage rigidities. In Colombia, the decline in the cyclicality of wages goes hand in hand with an increase in the cyclicality of employment. However, our analysis suggests that the decline of wage cyclicality was not accompanied by a parallel increase in the cyclicality of employment in Brazil. To view this formally, the first row in table 2 shows the differences in the cyclical behavior of employment (whole economy) before and after 1995. ${ }^{14}$ The density of the posterior difference is very close to zero $(-0.01$ at the median). These two sets of findings seem to be at odds with standard firm's cost minimization, which predicts that if wages become less flexible a larger bulk of the adjustment has to take place via quantities. ${ }^{15}$

One possible reconciliation of the two facts is that, as wages have become more rigid, a greater share of the adjustment has occurred via the intensive margin. If this is the case, working hours should have become more procyclical in the second part of the sample. The PME has information of working hours in the reference week, which allows us to do a three variable VAR including wages, output and the averaged hours worked for the employed population. Our results for the cyclicality of hours are shown in the panel A of figure 7. The figure suggests, as expected, that hours worked are procyclical with an estimated

13 Estimates for the service sector separately, available upon request, yield very similar results, with an elasticity that starts at 0.35 and declines steadily through the period.

14 We define the difference in the cyclical behavior of employment before and after Brazil macroeconomic stabilization $\left(D C_{s}^{l, y}\right)$ as follows:

$$
D C_{s}^{l, y}=1 / T_{1} \sum_{t_{1} \leq 1995} \rho_{t_{1}}^{l, y}-1 / T_{2} \sum_{t_{2}>1995} \rho_{t_{2}}^{w, y},
$$

where $T_{1}$ is the number of quarters before 1995 and $T_{2}$ the number of quarters after the macroeconomic stabilization.

15 However, Messina, Strozzi, and Turunen (2009) fail to find a positive association between employment and wage cyclicality across OECD countries. Their preferred explanation of this apparently puzzling result is policy complementarities. Their argument, following Bertola and Rogerson (1997), is that institutions that limit wage adjustment in OECD countries (e.g., unions) tend to coexist with regulations that prevent employment adjustments (e.g., employment protection). The proposed rationale seems of less relevance for developing countries, where unions are weaker and a large fraction of the labor force is informal and hence not covered by firing restrictions and other regulations. 
Figure 7. The Co-Movement of Employment and Output: Intensive vs. Extensive Margins and Differences Across Sectors

Panel A. Hours

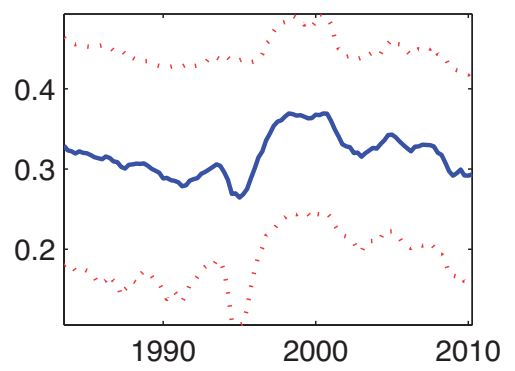

Panel C. Formal Employment

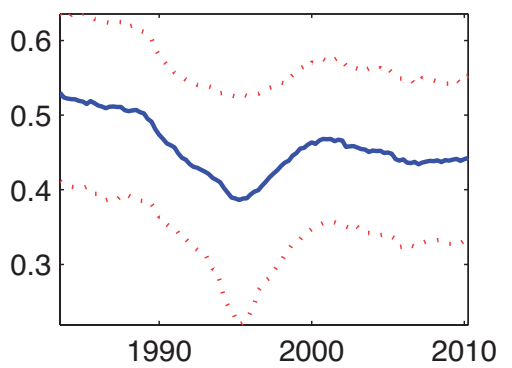

Panel B. Services

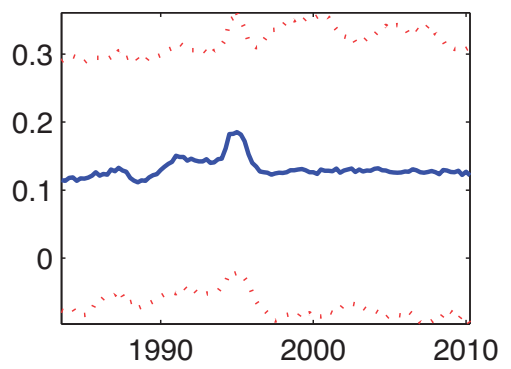

Panel D. Informal Employment

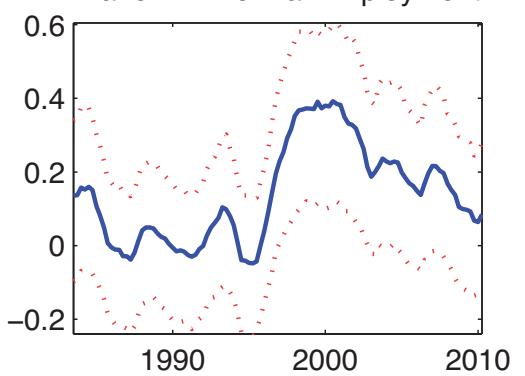

Notes: Each panel presents the results of the employment (hours in Panel A) co-movement with output from a 3 variables VAR that includes real wages. Panel A uses data for the whole economy. Wages and employment in Panels B-D correspond to the services (B), formal (C). and informal (D) sectors.

Source: Authors' elaboration based on data described in the appendix.

elasticity fluctuating around 0.3. There is weak evidence of an increase in the cyclicality of hours, especially after the 1995 stabilization. Thus, as wages became less procyclical hours became (weakly) more procyclical. Differences pre- and post-1995, presented on the second row of table 2 confirm a small increase over time. The posterior median difference pre- 1995 and post- 1995 is -0.028 , with the distribution tilted to the left of zero (the 16 th percentile is at -0.071 , while the 84 th percentile is 0.016 ).

In addition to the changes in the cyclicality of hours, at least two changes in the sector composition of Brazil may have a bearing on the cyclicality of employment: the formalization of employment in the 2000s and the secular tertiarization of the economy. Informality declined fast in the last 10 years. The share of workers employed with a formal contract remained essentially flat between 1995 and 2003 but increased by more than $20 \%$ between 2003 and 2012, from 48\% to 58\% (Ferreira, Firpo, and Messina 2014). ${ }^{16}$ The share of workers engaged in service activities increased more steadily through the period, from 55\% to $64 \%$ between 1995 and 2012. Changes in the composition of employment across sectors may affect the aggregate cyclicality of employment if there are differences across sectors in the levels of employment cyclicality or if the comovement of employment and output has evolved differently in different sectors.

Figure 7 shows the evolution of the employment cyclicality in the service sector (panel B), in the formal sector of the economy (panel C), and in the informal sector (panel D). The informal sector includes informal employees, that is, those working without a formal employment contract, and the self-employed. ${ }^{17}$

16 Formal workers are those who have a signed work card, "com carteira assinada," which gives them access to workrelated benefits.

17 Results with a more restrictive definition that excludes the self employed are very similar to those reported in the text. Each graph presents the comovement of employment and output in each sector obtained from a three variable VAR with wages, output, and employment. 
The comovement of employment and output in the service sector is much lower than in manufacturing and has remained essentially flat throughout the three decades. As we saw earlier, the employment cyclicality in the manufacturing sector fluctuates around 0.6. By contrast, the cyclicality of employment in services is estimated to be close to 0.1 . Thus, changes in the composition of employment towards the service sector are likely to reduce the cyclicality of employment in the whole economy. This is likely to have contributed to stabilizing the cyclicality of employment in the whole economy, as any forces that may have pushed upwards the correlation between employment and output may be masked by compositional changes.

The other compositional change, the formalization of the economy, is less likely to have played a major role. Employment in the formal sector is highly procyclical, with a correlation that fluctuates around 0.5 during the sample period. By contrast, the cyclicality of employment in the informal sector is close to zero up to 1995 but increases sharply thereafter, peaking at 0.4 during the early 2000s. The statistical significance of the increase in the cyclicality of informal employment post-1995 is corroborated in the last row of table 2. If anything, the formalization of employment of the last decade would have pushed for an even higher comovement between employment and output.

\section{Conclusions}

This paper studies changes in the cyclicality of wages in four Latin American countries during the last three decades. Our empirical approach relies on a vector autoregression model with both time-varying coefficients and residuals volatilities, which properly accounts for the dynamic properties of the underlying data series and their comovement, as well as for changes in the underlying relationship between the different variables.

We find that real wages are highly procyclical during the 1980s and early 1990s, but the responses of wages to business-cycle fluctuations decline in the second half of the 1990s and 2000s. This decline coincides with the disinflation and macroeconomic stabilization process in Latin America and is suggestive of a new role for downward wage rigidities in the region. Consistent with the existence of downward wage rigidities, we find in most cases an excess cyclicality of wages: the response of the real wage to output is stronger in expansions than in recessions.

Our results are primarily based on aggregated data for the manufacturing sector and, hence, present certain limitations. Compositional effects due to ins and outs of workers with different characteristics along the business cycle have been shown to downward bias estimates of the cyclicality of wages in developed economies. Higher volatility of manufacturing output than GDP may also offer a misleading picture of the behavior of the real wage in the whole economy. We have assessed the importance of these two potential composition biases using micro data in the case of Brazil. Perhaps surprisingly, we find that wages holding the composition of the labor force constant over the cycle behave very similarly to aggregate wages. This stands in contrast with previous findings for high-income countries. Similarly, the cyclicality of wages in the whole economy is similar to that reported for the manufacturing sector in Brazil. Although reassuring, we certainly cannot rule out these results to be different in the other countries studied, and hence, this is an issue that deserves further research.

Lastly, although the main focus of the study is to characterize changes over time in the cyclicality of wages, we also report estimates of the evolution of employment cyclicality. In Colombia, the decline of wage cyclicality is accompanied by a parallel increase in the cyclicality of employment. However, this is not the case in Brazil and Mexico, where the comovement of output and employment remained fairly stable. We examine the likely sources of this apparent puzzle in Brazil and find that the stability of employment cyclicality is likely due to changes in the intensive margin and compositional effects. First, working hours became weakly more procyclical during the decline of wage cyclicality. Secondly, there are marked differences in the cyclicality of employment of manufacturing and service sectors. Employment cyclicality 
in the service sector in Brazil is consistently lower than in manufacturing. Thus, the secular tertiarization of the economy is likely to have brought about a decline in the overall cyclicality of employment.

\section{Appendix}

\section{A.1. Data}

Brazil: Quantity of industrial production indexes are the "Produção industrial da indústria geral" from IGBE (the series can be found at http://www.ipeadata.gov.br) while GDP for the whole economy is obtained from Datastream. Nominal hourly wages and employment in the private sector, both for the manufacturing and whole economy, are obtained from the micro data of "Pesquisa Mensal de Emprego," a survey representative of the eight largest urban areas in Brazil. There is an important methodological change in 2000, with a new survey launched in 2001q1.

Chile: All series for Chile are taken from the Instituto Nacional de Estadística (INE). The industrial physical production index and the industrial employment index are representative for sectors CIIU Rev 2 311-390 between 1993-2002 and CIIU Rev 3 D15-D36 between 2002-2010. For the nominal remuneration per hour index, the series correspond to CIIU Rev 3. D15-D36. The employment series are calculated using the "Encuesta Nacional de Empleo" (ENE) and the "Nueva Encuesta Nacional de Empleo" (NENE) that changed in 2010. For wages the INE uses the "Encuesta Estructural de Remuneraciones y Costos Laborales"; and for industrial production they use the baseline of the sample of firms from the "Encuesta Industrial Anual".

Colombia: The Industrial employment index and the nominal industrial production index are taken from the Departamento Nacional de Estadística (DANE), and the nominal wage index is taken from the Central Bank. The indexes are defined for CIIU Rev 3. A.C. 1510-3690. The survey used to calculate the series is the "Muestra Mensual Manufacturera" (MMM).

Mexico: The employment index, volume of industrial production index, and the nominal remuneration index are taken from INEGI and are representative of 125 classes (SCIAN) from 1980-1995 and 205 classes from 1995-2008. All of the variables are calculated using the "Encuesta Industrial Mensual" (http://dgcnesyp.inegi.org.mx).

All employment indexes refer to number of people employed, not to employment rates, and all wage series refer to average hourly wages. For each country we have CPI price indexes to deflate the series. Finally, all series have been seasonally adjusted using X12.

\section{A.2. Model Specification}

Here we describe further details of model specification. Let $A_{t}=\left[A_{1, t} \ldots, A_{p, t}\right]$, and $\theta_{t}=\operatorname{vec}\left(\left[A_{0, t} A_{t}\right]^{\prime}\right)$, $v e c(\cdot)$ being the column stacking operator. We assume that the VAR parameters evolve as a random walk

$$
\theta_{t}=\theta_{t-1}+\omega_{t}
$$

where $\omega_{t}$ is a Gaussian white noise vector with zero mean and variance $\Omega$. Let $\Sigma_{t}=F_{t} D_{t} F_{t}^{\prime}$, where $F_{t}$ is lower triangular, with ones on the main diagonal, and $D_{t}$ a diagonal matrix. Let $\sigma_{t}$ be the vector of the diagonal elements of $D_{t}^{1 / 2}$ and $\phi_{i, t}, i=1, \ldots, n-1$ the column vector formed by the first $i$ elements of the $(i+1)$-th row of $F_{t}^{-1}$. We assume

$$
\begin{gathered}
\log \sigma_{t}=\log \sigma_{t-1}+\xi_{t} \\
\phi_{i, t}=\phi_{i, t-1}+\psi_{i, t}
\end{gathered}
$$

where $\xi_{t}$ and $\psi_{i, t}$ are Gaussian white noise vectors with zero mean and covariance $\Xi$ and $\Psi_{i}$. We assume that the elements of $\psi_{i, t}$ and $\psi_{j, t}$ are uncorrelated for $j \neq i$. Finally we assume that $\xi_{t}, \psi_{t}, \omega_{t}, \epsilon_{t}$ are also uncorrelated. 


\section{A.3. Prior Densities}

The model is estimated using the Gibbs sampling algorithm. We refer the reader to the online appendix of Gali and Gambetti (2015) for the details of the algorithm. Here we discuss some details of the prior densities. All of our assumptions about prior densities are quite standard in the literature. We assume that $\Omega, \Xi \Psi \theta_{0}, \varphi_{0}$, and $\log \sigma_{0}$ are independent. Let $W(S, d)$ denote Wishart distribution with scale matrix $S$ and degrees of freedom $d$. We assume

$$
\begin{gathered}
\theta_{0} \sim N\left(\hat{\theta}, \hat{V}_{\theta}\right) \\
\log \sigma_{0} \sim N\left(\log \hat{\sigma}_{0}, I_{n}\right) \\
\phi_{i 0} \sim N\left(\hat{\phi}_{i}, \hat{V}_{\phi_{i}}\right) \\
\Omega^{-1} \sim W\left(\underline{\Omega}^{-1}, \underline{\rho}_{1}\right) \\
\Xi^{-1} \sim W\left(\underline{\Xi}^{-1}, \rho_{-2}\right) \\
\Psi_{i}^{-1} \sim W\left(\underline{\Psi}_{i}^{-1}, \rho_{-3 i}\right)
\end{gathered}
$$

The parametrization of the scale matrices is: $\Omega=\rho_{-1}\left(\lambda_{1} \hat{V}_{\theta}\right), \underline{\Xi}=\rho_{-2}\left(\lambda_{2} I_{n}\right)$ and $\Psi_{i}=\rho_{-}{ }_{3 i}\left(\lambda_{3} \hat{V}_{\phi_{i}}\right)$.

The parameters $\hat{\phi}_{i}, \hat{V}_{\phi_{i}}, \log \hat{\sigma}_{0}, \hat{V}_{\phi_{i}}, \hat{V}_{\theta}, \hat{\theta}, \hat{V}_{\theta}$ are calibrated using a time invariant VAR estimated using the first 24 observations. The prior degrees of freedom are set equal to the size of the corresponding covariance matrix plus one. The parameters $\lambda_{i}$ are specified as follows.

- Brazil: $\lambda_{1}=0.0002, \lambda_{2}=0.0005, \lambda_{3}=0.0005$

- Chile: $\lambda_{1}=0.02, \lambda_{2}=0.02, \lambda_{3}=0.02$

- Colombia: $\lambda_{1}=0.02, \lambda_{2}=0.02, \lambda_{3}=0.02$

- Mexico: $\lambda_{1}=0.0002, \lambda_{2}=0.0005, \lambda_{3}=0.0005$

For Chile and Colombia parameters are smaller due to the shorter horizon. With a shorter horizon, the prior becomes more important. Therefore, a $\lambda$ parameter too small might have the effect of artificially eliminating posterior time variations. Therefore, we decide to be less conservative (higher $\lambda$ ) in the case of Chile and Colombia.

\section{References}

Abraham, K. G., and J. C. Haltiwanger. 1995. "Real Wages over the Business Cycle," Journal of Economic Literature 33 (3): 1215-64.

Aguilera, N., and G. Martinez. 2009. "Unemployment and Wages during Economic Cycles in the Americas," InterAmerican Conference on Social Security, Working Paper, 2009/02.

Bertola, G., and R. Rogerson. 1997. "Institutions and Labor Reallocation," European Economic Review 41 (6): 1147 71.

Bils, M. J. 1985. “Real Wages Over the Business Cycle: Evidence From Panel Data,” Journal of Political Economy 93 (4): 666-89.

Blanchard, O., and J. Galí. 2007. "Real Wage Rigidities and the New Keynesian Model," Journal of Money, Credit, and Banking 39 (supplement 1): 35-65.

Bosch, M., and W. F. Maloney. 2008. " Cyclical Movements in Unemployment and Informality in Developing Countries,” Policy Research Working Paper 4648, The World Bank, Washington, DC. 
Canova, F., and L. Gambetti. 2009. "Do Inflation Expectations Matter? The Great Moderation Revisited,” American Economic Journal: Macroeconomics 2 (3): 183-205.

Casarín, D., and L. Juárez. 2015. “Downward Wage Rigidities in the Mexican Labor Market 1996-2011,” Unpublished manuscript. Bank of Mexico.

Carneiro, A., P. Guimaraes, and P. Portugal. 2012. "Real Wages and the Business Cycle: Accounting for Worker and Firm Heterogeneity," American Economic Journal: Macroeconomics 4 (2): 133-52.

Clemens, M. P., and H.-M. Krolzig. 2003. "Business Cycle Asymmetries: Characterization and Testing Based on Markov-Switching Autoregressions,” Journal of Business and Economic Statistics 21 (1): 196-211.

Christiano, L. J., M. Eichenbaum, and C. L. Evans. 2005. "Nominal Rigidities and the Dynamic Effects of a Shock to Monetary Policy," Journal of Political Economy 113 (1): 1-45.

Den Haan, W. J. 2000. “The Co-movement between Output and Prices,” Journal of Monetary Economics 46 (1): 3-30.

Dickens, W. T., L. Goette, E. L. Groshen, S. Holden, J. Messina, M. E. Schweitzer, J. Turunen, and M. E. Ward. 2007. "How Wages Change: Micro Evidence from the International Wage Flexibility Project," Journal of Economic Perspectives 21 (2): 195-214.

Ferreira, F., S. Firpo, and J. Messina. 2014. “A More Level Playing Field? Explaining the Decline in Earnings Inequality in Brazil, 1995-2012,” Brooks World Poverty Institute Working Paper Series.

Galí, J., and L. Gambetti. 2009. "On the Sources of the Great Moderation,” American Economic Journal: Macroeconomics 1 (1): 26-57.

- 2015. "The Effects of Monetary Policy on Stock Market Bubbles: Some Evidence," American Economic Journal: Macroeconomics 7 (1): 233-57.

Harding, D., and A. Pagan. 2002. “Dissecting the Cycle: A Methodological Investigation,” Journal of Monetary Economics 49 (2): 365-81.

Holden, S., and F. Wulfsberg. 2009. "How Strong is the Macroeconomic Case for Downward Real Wage Rigidity?" Journal of Monetary Economics 56 (4): 605-15.

Messina, J., C. Strozzi, and J. Turunen. 2009. "Real Wages over the Business Cycle: OECD Evidence from the Time and Frequency Domains,” Journal of Economic Dynamics and Control 33 (6): 1183-1200.

Messina, J., and A. Sanz-de-Galdeano. (2014). "Wage Rigidity and Disinflation in Emerging Countries," American Economic Journal: Macroeconomics 6 (1): 102-33.

Neftçi, S. N. 1978. “A Time Series Analysis of the Real Wage-Employment Relationship,” The Journal of Political Economy 86 (1): 281-91.

Primiceri, G. E. 2005. “Time Varying Structural Vector Autoregressions and Monetary Policy,” Review of Economic Studies 72 (3): 821-52.

Smets, F., and R. Wouters. 2007. "Shocks and Frictions in U.S. Business Cycles: A Bayesian DSGE Approach," American Economic Review 97 (3): 586-606.

Solon, G., R. Barsky, and J. A. Parker. 1994. "Measuring the Cyclicality of Real Wages: How Important is Composition Bias?" The Quarterly Journal of Economics 109 (1), 1-25.

Schmitt-Grohé, S., and M. Uribe. (forthcoming). “Downward Nominal Wage Rigidity, Currency Pegs, and Involuntary Unemployment," Journal of Political Economy. 